\title{
Prevalence and phenotype of diabetes and prediabetes using fasting glucose vs HbA1c in a Caribbean population
}

\author{
Nigel Unwin ${ }^{1,2}$, Christina Howitt ${ }^{1}$, \\ Angela MC Rose ${ }^{1}$, T Alafia Samuels ${ }^{1}$, \\ Anselm JM Hennis ${ }^{1}$, Ian R Hambleton ${ }^{1}$ \\ ${ }^{1}$ George Alleyne Chronic Disease Research \\ Centre, Caribbean Institute for Health Research, \\ The University of the West Indies, Bridgetown, \\ Barbados \\ ${ }^{2}$ MRC Epidemiology Unit, University of \\ Cambridge, Cambridge, United Kingdom
}

\begin{abstract}
Background Both fasting plasma glucose (FPG) and HbAlc are recommended for the diagnosis of diabetes and prediabetes by the American Diabetes Association (ADA), and for diabetes by the World Health Organization. The ADA guidance is influential on clinical practice in many developing countries, including in the Caribbean and Latin America. We aimed to compare the prevalence and characteristics of individuals identified as having diabetes and prediabetes by FPG and HbAlc in a predominantly African ancestry Caribbean population.
\end{abstract}

Methods A representative population-based sample of 1234 adults ( $\geq 25$ years of age) resident in Barbados was recruited. Standard methods with appropriate quality control were used to collect data on height, weight, blood pressure, fasting lipids and history of diagnosed diabetes, and to measure fasting glucose and HbAlc. Those with previously diagnosed diabetes $(n=192)$ were excluded from the analyses. Diabetes was defined as: FPG $\geq 7.0 \mathrm{mmol} / \mathrm{L}$ or $\mathrm{HbAlc}$ $\geq 6.5 \%$; prediabetes as: FPG $\geq 5.6$ to $<7 \mathrm{mmol} / \mathrm{L}$ or $\mathrm{HbAlc} \geq 5.7$ to $<6.5 \%$.

Results Complete data were available on 939 participants without previously diagnosed diabetes. The prevalence of undiagnosed diabetes was higher, but not significantly so, by HbAlc $(4.9 \%, 95 \%$ CI $3.5,6.8)$ vs FPG $(3.5 \%, 2.4,5.1)$. Overall 79 individuals had diabetes by either measure, but only 21 on both. The prevalence of prediabetes was higher by HbAlc compared to FPG: $41.7 \%(37.9,45.6)$ vs $15.0 \%(12.8,17.5)$. Overall 558 individuals had prediabetes by either measure, but only 107 on both. HbAlc, but not FPG, was significantly higher in women than men; and FPG, but not HbAlc, was significantly associated with raised triglycerides and low HDL cholesterol.

Conclusion The agreement between FPG and HbAlc defined hyperglycaemia is poor. In addition, there are some differences in the phenotype of those identified, and HbAlc gives a much higher prevalence of prediabetes. The routine use of HbAlc for screening and diagnosis in this population would have major implications for clinical and public health policies and resources. Given the lack of robust evidence, particularly for prediabetes, on whether intervention in the individuals identified would improve outcomes, this approach to screening and diagnosis cannot be currently recommended for this population. 
Globally there are estimated to be over 400 million people with diabetes, and of these 4 out of 5 live in low and middle income countries [1]. Diabetes is estimated to cause 5 million deaths per year, and is a major contributor to premature adult mortality [1]. A substantial proportion of people with Type 2 diabetes, which comprises approximately 90-95\% of all persons with diabetes, are undiagnosed. This undiagnosed proportion can be as high as $80-90 \%$ in some of the poorest settings, such as in many of the countries of sub-Saharan Africa, and is typically around 20-30\% in the world's richest countries, including most of those in Western Europe and North America [1].

In addition to individuals with diabetes, there are those with 'prediabetes' [2], also known as 'intermediate hyperglycaemia' [3]. These individuals have glucose levels that are above normal, but below the diagnostic threshold for diabetes. They are at increased risk of developing diabetes. There are three broad categories of prediabetes, and there is excellent evidence that among persons with one category (impaired glucose tolerance, which is based on the 2-hour post challenge result in an oral glucose tolerance test) the risk of developing diabetes can be substantially lowered through changes in diet and physical activity or the use of metformin [4].

There have been two major changes over the past 20 years to the diagnostic criteria for diabetes. In 1997 the American Diabetes Association (ADA) lowered the diagnostic cut-point for fasting plasma glucose from $7.8 \mathrm{mmol} / \mathrm{L}$ to $7 \mathrm{mmol} / \mathrm{L}$, and recommended that fasting glucose becomes the main diagnostic test, rather than the more time-consuming and expensive oral glucose tolerance test, which includes collection of a fasting sample and a sample 2 hours after a 75g glucose load [5]. In 2009, the International Expert Committee, which included the ADA, recommended that the diagnosis could also be made using glycated haemoglobin, HbAlc, at a cut-point of 6.5\% [6]. HbAlc reflects the exposure of red cells to glucose over their lifetime. In a person with normal haemoglobin the average lifespan of red cells is around 120 days [7], with the average age of red cells in circulation being in the order of 40-60 days [8]. HbAlc therefore can be interpreted as reflecting average glucose levels over this time. The major advantage of $\mathrm{HbAlc}$ is that it does not require the person to be fasting, but it has the disadvantage of being more expensive to measure, and that the result can be influenced by medical conditions that affect red cell turnover and/or produce abnormal haemoglobin [9]. The World Health Organization (WHO) followed in lowering the cut-point for fasting glucose and in accepting HbAlc as a diagnostic test in 1999 [10] and 2011 [9], respectively. However, unlike the ADA, WHO still emphasizes the desirability of continuing to use an oral glucose tolerance test as the gold standard for the diagnosis of diabetes, while acknowledging that the use of fasting glucose or HbAlc is more practical.

While the ADA and WHO diagnostic criteria for diabetes are identical, there are two major differences when it comes to the diagnosis of prediabetes (the ADA term) or intermediate hyperglycaemia (the WHO term). First, the ADA cut-point for prediabetes based on fasting plasma glucose (FPG) at $5.6 \mathrm{mmol} / \mathrm{L}$ [11] is lower than that recommended by WHO at $6.1 \mathrm{mmol} / \mathrm{L}$ [3]. Second, WHO does not believe that there is enough evidence to recommend using HbAlc to diagnose prediabetes [9], whereas the ADA does and defines it as an HbAlc level from 5.7 to $<6.5 \%$ [11]. It is relevant to the aims of the work present here to note that the ADA recommends that all people with prediabetes, whatever the method of diagnosis, are entered into a structured diabetes prevention programme [11]. Thus, if changing the approach to diagnosis changes the numbers of individuals identified, this would have implications for health care resources.

The Caribbean is an ethnically and linguistically diverse region [12], that includes 18 English-speaking countries and territories that are part of the Caribbean Community (CARICOM) [13] and have some of the highest rates of diabetes and diabetes mortality in the Americas [1,14]. Barbados, where the work described here was undertaken, is part of the English-speaking Caribbean and a member of CARICOM. It is an independent country, with a population of around 280000 , over $90 \%$ of whom are of African ancestry [15]. While the diagnosis of diabetes in Barbados and other parts of the Caribbean to date has largely relied on fasting glucose, ADA guidance [11] is highly respected and influential, and the greater availability of accessible and good quality HbAlc assays means that it is increasingly being used.

In this paper we make use of a recently conducted population-based survey [16] in which all participants had both FPG and HbAlc measured. Our aim was to assess what difference, if any, would using HbAlc rather than FPG make to the identification of diabetes and prediabetes. Specifically, we sought to determine whether there would be a difference in prevalence of the conditions, the individuals identified and the characteristics of those individuals. Our aim was not to determine which measure better predicts complications or progression (that would require a very different type of study), but rather to determine what the local policy and resource implications might be of using one approach compared to the other. This, as far as we can determine, is the first study of its type conducted in the Caribbean. 


\section{METHODS}

\section{Overview of the study design and data collection}

The Health of the Nation survey was a cross-sectional study of the Barbadian population aged 25 years and older, which aimed to provide estimates of the prevalence and social distribution of non-communicable diseases (NCDs) and their risk factors. Data were collected for 1234 participants on health conditions and behaviours, as well as sociodemographic information. Data collection took place between September 2011 and May 2013. The survey methods have been described in detail elsewhere [16] and are summarised here.

On behalf of the Ministry of Health of the Government of Barbados, and in collaboration with the Barbados Statistical Service, a multistage sampling process was used, with enumeration districts (EDs) selected with a probability proportional to their population size, households randomly selected within each ED, and a single eligible participant randomly selected from each household using the Kish method [17]. Staff from the Barbados Statistical Service made the first contact with each household and, if permission was given, the household details were passed on to members of the Health of the Nation survey team.

Data collection took place in participants' homes across two visits. At the first visit a standard questionnaire was completed by interview. Items collected included whether the participant had been told by a doctor that they had diabetes, and if so what type of treatment they were on. At this first visit, height, weight, waist and hip circumferences were recorded, and blood pressure was measured using an Omron HEM-705CP digital machine. Standard protocols were followed for all measurements, and data collection staff were trained and accredited in their use.

At the end of this first visit a second early morning visit was arranged for the collection of a venous blood sample, typically on the day after the first visit. The participant was instructed to fast overnight for at least 9 hours, drinking nothing other than water. The venous sample was collected into two tubes: a sodium fluoride tube and an EDTA tube. The sodium fluoride tube was placed immediately on wet ice, and the EDTA tube was placed in a cool box, which contained ice packs.

\section{Assays of glucose, HbAlc and lipids}

The sodium fluoride tube was kept on wet ice until its contents were analysed for plasma glucose later that morning. This analysis was undertaken at the Barbados Reference Laboratory using the glucose hexokinase method on Roche Cobas 6000 (Roche Diagnostics, Mannheim, Germany).

The sample in the EDTA tube was used for HbAlc and lipid analyses. All analyses were conducted during the same morning as the sample collection. Lipids (total cholesterol, HDL cholesterol and triglycerides) were analysed using a Reflotron biochemical analyser (Roche Diagnostics, Mannheim, Germany). HbAlc was analysed using a DCA 2000 analyser (Siemens Health Care Diagnostics, Munich, Germany), a method certified by NGSP and directly traceable to the DCCT reference [18] and which is not affected by common haemoglobin variants such as $\mathrm{HbC}$ and $\mathrm{HbS}$ [19]. Manufacturers' recommended quality control procedures for all biochemical assays were followed throughout.

The Reflotron and DCA 2000 analyser were used as they provide assay methods that are practical, affordable, widely used in surveys and known to be of good quality compared to laboratory standard methods [20-23]. However, we wished to be able to align the HbAlc and lipid results with those from the Barbados Reference Laboratory, an internationally accredited laboratory (with the College of American Pathologists - CAP). This was achieved by analysing duplicate samples, 56 for HbAlc and 50 for lipids. For HbAlc, this was done at the time of venepuncture by collecting blood into two separate EDTA tubes, with one tube going to the reference laboratory, where HbAlc was measured using high performance liquid chromatography (HPLC). For the lipids, 50 plasma aliquots, which had been stored at minus $80^{\circ} \mathrm{C}$, were assayed in the reference laboratory for total, HDL and LDL cholesterol and triglycerides on a Roche Cobas 6000 analyzer.

Details of the comparison between the values of HbAlc and the lipids assessed by the two different assay methods are given in the supplementary material. There were small but statistically significant differences between the results from the survey assay methods and those in the Barbados Reference Laboratory. As would be expected, there was inter-individual variation in the size of the differences. These are expressed as the standard deviation of the differences [24] and show that 95\% of the differences for the lipids lay 
within 0.2 and $0.7 \mathrm{mmol} / \mathrm{L}$ (Table S1 in Online Supplementary Document) of the mean, and for HbAlc within 1\% (Table S1 in Online Supplementary Document). As described in the supplement, simple linear regression equations were applied to the survey results to align them with reference laboratory values.

\section{Statistical analyses}

Data were analysed using Stata statistical software (version 13, StataCorp, College Station, Texas). Weights were applied to account for the sampling design, non-response at the ED level, and to match the age and sex distribution of the Barbadian population according to the 2010 census [15]. As described elsewhere, compared with the official population, provided by the 2010 Barbados Population and Housing Census, the survey generally under-sampled young adults and oversampled the elderly, and more women than men took part. These discrepancies were addressed by the weighting scheme, full details of which are available on-line in the publication by Howitt et al [16].

Categories of hyperglycaemia were defined according to the criteria of the ADA [11] and the WHO [3,9]. Diabetes was defined, according to both ADA and WHO criteria, as FPG $\geq 7.0 \mathrm{mmol} / \mathrm{L}$ or HbAlc $\geq 6.5 \%$. Prediabetes according to ADA criteria was defined as FPG $\geq 5.6$ to $<7 \mathrm{mmol} / \mathrm{L}$ or $\mathrm{HbAlc} \geq 5.7$ to $<6.5 \%$. Prediabetes (impaired fasting glucose) according to WHO criteria was defined as FPG of $\geq 6.1$ to $<7 \mathrm{mmol} / \mathrm{L}$.

Those with previously diagnosed diabetes $(n=192)$ were excluded from the analyses in which the classification and characteristics according to FPG and HbAlc values were compared. Agreement was investigated in unweighted analyses in which categories based on FPG and HbAlc were cross-tabulated. Unweighted kappa statistics, using the Kappa command in Stata, were calculated.

The characteristics of individuals with ADA-defined hyperglycaemia were investigated as follows. First, differences (with 95\% confidence intervals) in means and proportions between individuals with hyperglycaemia (ie, above the prediabetes cut-point) and normoglycaemia were examined. This was performed separately for the HbAlc and FPG defined categories. Age and sex were compared, plus anthropometric and biological variables commonly associated with hyperglycaemia [25]: body mass index, waist circumference, systolic and diastolic blood pressure, HDL cholesterol and triglycerides. The association of normo/hyperglycaemia with hypertension, as a binary variable (yes/no), was also examined, in order to allow for the fact that some individuals may have normal blood pressure readings because they are on treatment. Hypertension was defined as being on [or using prescribed] medication for hypertension and/or systolic blood pressure $>140 \mathrm{~mm} \mathrm{Hg}$ and/or diastolic blood pressure $>90 \mathrm{~mm} \mathrm{Hg}$. Second, logistic regression was undertaken to identify which characteristics were independently associated with hyperglycaemia. A backward step selection process was used, starting with all the independent variables in the model and removing the least significantly associated variable at each step. This was halted when all variables in the model were associated with a $P$ value of at least $<0.05$. All the analyses were undertaken using the survey module in Stata, in order to apply appropriate weights given the sampling design, non-response and age and sex distribution of the Barbados population (as described above). Model specification was evaluated using the link test and goodness of fit using the 'estat gof' command [26].

\section{Ethical considerations}

Written informed consent was obtained from all participants. The study was approved by the Research Ethics Committee of the University of the West Indies, Cave Hill and the Barbados Ministry of Health. All persons in the study found to have abnormal results, including abnormal HbAlc or FPG, were informed and advised to seek medical advice and further investigation as needed.

\section{RESULTS}

There was a total of 1234 respondents (470 men and 764 women). Out of 2277 eligible households contacted by the Barbados Statistical Service, 1646 (72.3\%) agreed to having their details passed on to the Health of the Nation survey; from these, 1234 (75.0\%) individuals participated in the study (see Howitt et al. for full details [16]).

Diagnosed diabetes was reported by 192 participants, $11.4 \%$ (95\% confidence interval (CI) 8.3, 15.5) of men and 15.8\% (95\% CI 13.1, 18.8) of women (Table 1). Of the 1042 without a previous diagnosis of diabetes, complete data on fasting glucose and HbAlc were available on 939 (90\%). In these individuals, the prevalence of previously undiagnosed diabetes ranges from 3.5\% (95\% CI 2.4. 5.1) (FPG criterion in 
Table 1. Prevalence of categories of diabetes and prediabetes in Barbadian adults (25 years and over)*

\begin{tabular}{|c|c|c|c|}
\hline & Men $(n=430)$ & Women ( $=701)$ & $A u(n=1131)$ \\
\hline \multicolumn{4}{|l|}{ Diagnosed diabetes $(n=192)$ : } \\
\hline On hypoglycaemic medication & $9.2(6.6,12.8)$ & $13.8(11.4,16.7)$ & $11.7(9.8,13.8)$ \\
\hline Not on medication & $2.1(1.1,4.1)$ & $1.9(1.0,3.7)$ & $2.0(1.2,3.3)$ \\
\hline All & $11.4(8.3,15.5)$ & $15.8(13.1,18.8)$ & $13.8(11.7,16.2)$ \\
\hline \multicolumn{4}{|l|}{ Undiagnosed diabetes: $\dagger$} \\
\hline $\mathrm{FPG} \geq 7.0 \mathrm{mmol} / \mathrm{L}$ & $3.3(2.0,5.5)$ & $3.7(2.2,6.3)$ & $3.5(2.4,5.1)$ \\
\hline HBAlc $\geq 6.5 \%$ & $3.9(2.3,6.5)$ & $5.7(3.9,8.3)$ & $4.9(3.5,6.8)$ \\
\hline On either of above & $5.7(3.9,8.3)$ & $7.3(5.0,10.4)$ & $6.5(4.9,8.6)$ \\
\hline \multicolumn{4}{|l|}{ Prediabetes (WHO criteria): } \\
\hline FPG $\geq 6.1$ to $<7 \mathrm{mmol} / \mathrm{L}$ & $5.5(3.5,8.5)$ & $4.4(2.8,6.7)$ & $4.9(3.5,6.9)$ \\
\hline \multicolumn{4}{|l|}{ Prediabetes (ADA criteria): $\dagger$} \\
\hline FPG $\geq 5.6$ to $<7 \mathrm{mmol} / \mathrm{L}$ & $16.7(12.9,21.2)$ & $13.6(10.6,17.2)$ & $15.0(12.8,17.5)$ \\
\hline HBAlc $\geq 5.7$ to $<6.5 \%$ & $39.7(33.8,46.0)$ & $43.4(39.8,47.2)$ & $41.7(37.9,45.6)$ \\
\hline On either of above & $42.2(35.9,48.8)$ & $45.8(42.2,49.4)$ & $44.1(40.5,47.9)$ \\
\hline
\end{tabular}

FPG - fasting plasma glucose, HBAlc - haemoglobin Alc, ADA - American Diabetes Association

*Figures are percentages (95\% confidence intervals), and are weighted for sampling design, non-response and the age structure of the Barbados adult population.

†See Table 2 for numbers of individuals (unweighted) by category.

men and women) to $7.3 \%$ (95\% CI 5.0, 10.4) (FPG and/or HbAlc criterion in men and women). The prevalence of previously undiagnosed diabetes is higher by the HbAlc criterion compared to the FPG in both women and men; and higher in women compared to men by both the HbAlc and FPG criteria. However, the confidence intervals are wide and overlapping.

The prevalence of prediabetes differs markedly by the three different sets of criteria (Table 1 ). The lowest prevalence is for the WHO FPG criterion, with an overall prevalence in men and women of 4.9\% (95\% CI 3.5, 6.9). Applying the ADA FPG criterion triples the prevalence, to $15.0 \%$ (95\% CI 12.8, 17.5). Applying the ADA HbAlc criterion gives more than double the ADA FPG prevalence, at $41.7 \%(95 \% \mathrm{CI}$ $37.9,45.6)$. Defining prediabetes based on either FPG or HbAlc gives a prevalence of $44.1 \%$ (95\% CI $40.5,47.9)$.

The agreement between diabetes and prediabetes according to ADA FPG vs HbAlc criteria is poor, reflected by low kappa values (Table 2). For example, there are 43 individuals with previously undiagnosed diabetes based on FPG, and 57 based on HbAlc, but only 21 on both (kappa 0.39, 95\% CI 0.32, 0.45). With prediabetes there are 170 based on FPG, 495 on the HbAlc, and only 107 on both (kappa 0.14, 95\% CI 0.10, 0.19).

Table 2. Agreement between categories of diabetes and prediabetes based on fasting plasma glucose (FPG) and HbAlc criteria*

\begin{tabular}{|c|c|c|c|c|}
\hline \multirow[b]{2}{*}{ HbAlc: } & \multicolumn{4}{|c|}{ FPG } \\
\hline & Not diabetes & Diabetes & Total & \\
\hline Not diabetes & 860 & 22 & 882 & \\
\hline Diabetes & 36 & 21 & 57 & \\
\hline Total & 896 & 43 & 939 & \\
\hline \multirow[t]{2}{*}{ Kappa (95\% CI) } & \multicolumn{3}{|c|}{$0.39(0.32,0.45)$} & \\
\hline & \multicolumn{4}{|c|}{ ADA Categories based on FPG } \\
\hline ADA categories based on HbAlc & Normal & Prediabetes & Diabetes & Total \\
\hline Normal & 342 & 37 & 8 & 387 \\
\hline Prediabetes & 374 & 107 & 14 & 495 \\
\hline Diabetes & 10 & 26 & 21 & 57 \\
\hline Total & 726 & 170 & 43 & 939 \\
\hline Kappa (95\% CI) & 0.1 & $4(0.10,0.19)$ & & \\
\hline
\end{tabular}

Anthropometric and biological characteristics of those without a previous diagnosis of diabetes are summarised in Table 3. There are notable differences between men and women, with women having a significantly (based on the lack of overlap between $95 \%$ confidence intervals) higher body mass index, HbAlc, total and HDL cholesterol, but similar fasting glucose, and lower triglycerides and lower mean systolic blood pressure. A higher proportion of women than men are on treatment for hypertension. The prevalence of obesity (BMI $\geq 30 \mathrm{~kg} / \mathrm{m}^{2}$ ) is $43.5 \%(95 \%$ CI 39.1, 48.0) in women and $23.2 \%(95 \%$ CI $18.4,28.8)$ in men.

Selected characteristics of those with ADA-defined hyperglycaemia compared to those with normoglycaemia by FPG and HbAlc criteria are shown in Table 4. Older age, higher body mass index, waist circumference and blood 
Table 3. Characteristics of those without previously diagnosed diabetes, and with complete fasting glucose and HbAlc data*

Age in years (n, column \%):

\begin{tabular}{|c|c|c|c|}
\hline $25-44$ & $139(38.5)$ & $252(43.6)$ & $391(41.6)$ \\
\hline $45-64$ & $155(42.9)$ & $237(41.0)$ & $392(41.8)$ \\
\hline $65+$ & $67(18.6)$ & $89(15.4)$ & $156(16.6)$ \\
\hline All & $361(100.0)$ & $578(100.0)$ & $939(100.0)$ \\
\hline \multicolumn{4}{|l|}{ Glucose \& HbAlc: } \\
\hline Mean fasting glucose (mmol/L) & $5.2(5.1,5.3)$ & $5.2(5.1,5.4)$ & $5.2(5.2,5.3)$ \\
\hline Mean HbAlc (\%) & $5.7(5.6,5.7)$ & $5.8(5.7,5.9)$ & $5.7(5.7,5.8)$ \\
\hline \multicolumn{4}{|l|}{ Other: } \\
\hline \multicolumn{4}{|l|}{ Anthropometry } \\
\hline Mean BMI $\left(\mathrm{kg} / \mathrm{m}^{2}\right)$ & $26.4(25.7,27.1)$ & $29.8(29.1,30.5)$ & $28.2(27.8,28.6)$ \\
\hline Mean waist circumference $(\mathrm{cm})$ & $90.1(88.1,92.0)$ & $92.6(91.2,94.1)$ & $92.1(91.1,93.1)$ \\
\hline \multicolumn{4}{|l|}{ Blood pressure: } \\
\hline Mean sBP (mmHg) & $131.0(129.1,133.0)$ & $126.5(124.5,128.6)$ & $128.7(127.3,130.1)$ \\
\hline Mean dBP (mmHg) & $77.8(76.3,79.3)$ & $76.8(75.7,77.8)$ & $77.3(76.4,78.2)$ \\
\hline$\%$ On treatment for hypertension & $14.1(10.9,18.1)$ & $25.3(20.4,30.8)$ & $19.9(16.7,23.6)$ \\
\hline \multicolumn{4}{|l|}{ Lipids: } \\
\hline Mean total cholesterol $(\mathrm{mmol} / \mathrm{L})$ & $4.6(4.5,4.7)$ & $4.9(4.8,4.9)$ & $4.7(4.7,4.8)$ \\
\hline Mean HDL cholesterol $(\mathrm{mmol} / \mathrm{L})$ & $1.28(1.25,1.31)$ & $1.40(1.38,1.43)$ & $1.34(1.32,1.36)$ \\
\hline Mean triglycerides (mmol/L) & $0.96(0.92,1.00)$ & $0.88(0.85,0.92)$ & $0.92(0.90,0.94)$ \\
\hline
\end{tabular}

HBAlc - haemoglobin Alc, BMI - body mass index, sBP - systolic blood pressure, dBP - diastolic blood pressure, HDL - high density lipoprotein

*103 individuals of the 1042 without previously diagnosed diabetes had missing fasting glucose and/or HbAlc values. All figures, with the exception of the numbers by age group, are weighted for the sampling design, non-response, and the age structure of the Barbados adult population.

Table 4. Comparison of selected characteristics between groups with normal and raised fasting glucose or HbAlc based on ADA criteria*

\begin{tabular}{|c|c|c|c|}
\hline & Normal & Raised & Absolute Difference (95\% Cl) \\
\hline \multicolumn{4}{|l|}{ Fasting glucose: } \\
\hline Age (years) & $45.2(0.8)$ & $53.7(1.5)$ & $8.5(5.5,11.4)$ \\
\hline Female sex (\%) & $52.7 \%$ & $50.1 \%$ & $-2.8(-12.3,6.7)$ \\
\hline BMI $\left(\mathrm{kg} / \mathrm{m}^{2}\right)$ & $27.5(0.4)$ & $30.1(0.6)$ & $2.5(1.0,4.0)$ \\
\hline Waist $(\mathrm{cm})$ & $89.8(0.8)$ & $97.0(1.2)$ & $7.0(3.9,10.2)$ \\
\hline sBP (mmHg) & $126.6(0.7)$ & $135.9(1.9)$ & $9.2(5.3,13.0)$ \\
\hline $\mathrm{dBP}(\mathrm{mmHg})$ & $76.4(0.5)$ & $80.3(1.1)$ & $4.1(1.8,6.3)$ \\
\hline Hypertension (\%)† & 28.4 & 56.8 & $28.3(19.0,37.6)$ \\
\hline HDL cholesterol (mmol/L) & $1.36(0.01)$ & $1.29(0.02)$ & $-0.07(-0.12,-0.02)$ \\
\hline Triglycerides $(\mathrm{mmol} / \mathrm{L})$ & $0.97(0.02)$ & $1.17(0.06)$ & $0.20(0.07,0.34)$ \\
\hline \multicolumn{4}{|l|}{ HbAlc: } \\
\hline Age (years) & $41.3(0.8)$ & $51.9(0.9)$ & $10.9(8.6,13.2)$ \\
\hline Female sex (\%) & $46.8 \%$ & $56.6 \%$ & $9.6(2.5,16.6)$ \\
\hline BMI $\left(\mathrm{kg} / \mathrm{m}^{2}\right)$ & $26.5(0.4)$ & $29.5(0.4)$ & $3.0(1.7,4.2)$ \\
\hline Waist $(\mathrm{cm})$ & $87.0(1.0)$ & $94.9(0.8)$ & $7.7(4.9,10.5)$ \\
\hline $\mathrm{sBP}(\mathrm{mmHg})$ & $124.8(1.0)$ & $131.8(0.9)$ & $7.4(4.8,10.1)$ \\
\hline $\mathrm{dBP}(\mathrm{mmHg})$ & $75.9(0.8)$ & $78.4(0.6)$ & $2.8(1.0,4.7)$ \\
\hline Hypertension $(\%) \dagger$ & 22.2 & 44.9 & $22.7(15.3,30.0)$ \\
\hline HDL cholesterol (mmol/L) & $1.34(0.02)$ & $1.34(0.02)$ & $0.00(-0.05,00.1)$ \\
\hline Triglycerides $(\mathrm{mmol} / \mathrm{L})$ & $0.96(0.03)$ & $1.05(0.03)$ & $0.09(0.00,00.2)$ \\
\hline
\end{tabular}

HBAlc - haemoglobin Alc, BMI - body mass index, sBP - systolic blood pressure, dBP - diastolic blood pressure, HDL - high density lipoprotein

*Figures are means (standard error) unless otherwise indicated.

$\dagger$ On BP lowering medication and/or blood pressure $\geq 140 / 90$. See text for details. 
Table 5. Results of logistic regression to identify independent associations between hyperglycaemia and the characteristics in Table 4

\begin{tabular}{lcc} 
& Odos Ratlo & 95\% Cls \\
Fasting glucose: & & \\
\hline Age (years) & 1.03 & $1.01,1.04$ \\
\hline Waist (cm) & 1.03 & $1.01,1.05$ \\
\hline Hypertension (Y/N) & 2.03 & $1.25,3.30$ \\
\hline Triglycerides (mmol/L) & 1.46 & $1.07,2.00$ \\
\hline HbAlc: & & \\
\hline Age (years) & 1.05 & $1.04,1.07$ \\
\hline Female sex & 1.40 & $1.03,1.91$ \\
\hline Waist (cm) & 1.04 & $1.02,1.06$ \\
\hline HbAlc (model with sex specific "high waist"*): & \\
\hline Age (years) & 1.06 & $1.04,1.07$ \\
\hline Female sex & 1.25 & $0.94,1.66$ \\
\hline High waist (Y/N) & 2.32 & $1.50,3.58$ \\
\hline
\end{tabular}

HBAlc - haemoglobin Alc

$* \geq 94 \mathrm{~cm}$ in women; $\geq 102 \mathrm{~cm}$ in men. pressure are all related to both FPG and HbAlc categories of hyperglycaemia. Higher triglyceride, and lower HDL cholesterol levels are associated with FPG, but not HbAlc, defined hyperglycaemia. Female sex is associated with HbAlc, but not FPG, defined hyperglycaemia.

Backward step logistic regression, as described in the methods section and starting with all the variables shown in Table 4 was undertaken to identify factors independently associated with FPG and HbAlc categories of hyperglycaemia. The FPG category was independently associated with age, waist circumference, hypertension and triglycerides (Table 5). The HbAlc category was associated with age, waist circumference and female sex, but not blood pressure, HDL cholesterol or triglycerides. In further analysis, waist circumference was entered into the model for $\mathrm{HbAlc}$ as a binary variable using sex specific cut-points (94 cm for women, $102 \mathrm{~cm}$ for men [27]). As shown in Table 5, this had the effect of reducing the association with female sex (odds ratio (OR) $1.25,95 \%$ CI $0.94,1.66$ ).

\section{DISCUSSION}

In the first study of its type in the Caribbean, we compared the prevalence and agreement of diabetes and prediabetes as defined by FPG and HbAlc. We found that HbAlc gave a higher prevalence of both diabetes (non-significant) and prediabetes. Applying the ADA criteria, the prevalence of prediabetes was more than twice as high based on HbAlc compared to fasting glucose. The agreement between the two methods of classification was poor. There were also differences in the factors associated with HbAlc and FPG-defined hyperglycaemia. HbAlc, but not FPG, defined hyperglycaemia was associated with female sex. Raised FPG, but not HbAlc, defined hyperglycaemia was associated with raised triglycerides and hypertension. At a population level, therefore, there are important differences in terms of prevalence and the characteristics of the individuals identified.

While both HbAlc and FPG are recommended by the ADA and WHO for the diagnosis of diabetes, and by the ADA for the diagnosis of prediabetes, it is unclear whether one should be preferred over the other. Analyses of cross-sectional data from nine studies across five countries found that both FPG and HbAlc at the currently recommended diagnostic cut-points for diabetes were strongly associated with an increased risk of diabetic retinopathy, whereas the 2-hour glucose from an oral glucose tolerance test was not [28]. Prediabetes, whether defined by HbAlc or FPG, is associated with an increased risk of developing diabetes [29]. However, it does not appear that one test is better than the other at predicting harder adverse outcomes, such as death or incident cardiovascular disease. For example, neither adds much to the prediction of cardiovascular events when other established cardiovascular risk factors are taken into account [30].

It is also unclear, given the currently available evidence, whether the lifestyle and pharmacological interventions that have been shown to substantially reduce the incidence of diabetes in those with impaired glucose tolerance [4], which requires an oral glucose tolerance test for diagnosis, are also effective in those with prediabetes based on FPG or HbAlc. It seems a reasonable assumption that they would be, and indeed guidance is based on this assumption [11]. However, hard evidence is lacking, and what does exist suggests that in the case of impaired fasting glucose these interventions may be either ineffective or much less effective [31,32]. Comparable studies targeting prediabetes based on HbAlc do not exist [29].

Other studies have also investigated differences in the prevalence of diabetes and prediabetes by different measures of glycaemia, whether HbAlc, FPG, or the use of an oral glucose tolerance test. A pooled analysis to investigate the impact on diabetes prevalence, based on 63 health examination surveys, found differences in prevalence (both higher and lower), with similar prevalences in only a minority (15\%) [33]. Differences in agreement between studies were significantly, but weakly, related to population differences in body mass index and gross domestic product [33]. For example, in a pooled regression analysis, the prevalence of diabetes by HbAlc, while controlling for the prevalence by FPG, was positively related with age, mean body mass index, and gross domestic project [33]. 
Studies reporting differences in the prevalence of prediabetes by FPG and HbAlc have also found differences in both directions. In the Canadian Health Measures Survey, for example, differences in the prevalence of prediabetes in adults based on ADA criteria by FPG and HbAlc are similar to what we describe here: 13\% using FPG vs 33\% with HbAlc [34]. In the United States (US) NHANES study, by contrast, the prevalences of prediabetes were almost the reverse: $28.7 \%$ with FPG and $12.4 \%$ with HbAlc [35]. The reasons for these differences are not clear based on the published data. Neither study presented a comparison by sex, nor compared the characteristics of those with differently defined prediabetes. The higher prevalence of obesity in the US (30-33\%) compared to Canada (20-22\%) [36] is not obviously related to these differences. Interestingly, in a relatively small study $(n=216)$ of predominantly male (mean age 37 years) African migrants to the US, the prevalence of hyperglycaemia (taking the figures from Table 2 in the paper) [37] using ADA criteria was 13\% by FPG and 35\% by HbAlc, similar to what we report in our study here.

It is also relevant to our findings to note that some analyses, in particular based on data from the US NHANES study, have described higher levels of HbAlc in black compared to white participants ('black' and 'white' being the terms used in the paper) independent of differences in fasting and post challenge glucose [38]. Similarly, in the Atherosclerosis Risk in Communities Study, HbAlc levels were higher in black compared to white participants independent of fasting glucose level [39]. The American Diabetes Prevention Program (conducted in adults with impaired glucose tolerance) also reported differences by ethnicity in average HbAlc levels, with higher levels in black compared to white participants, and these were independent of differences in obesity, fasting and post challenge glucose, and insulin resistance [40]. It may be, therefore, that relationships between measures of glucose (including fasting and post challenge) and $\mathrm{HbAlc}$ differ by ethnic group, with a higher HbAlc level in people of black African origin compared to people of white European origin $[41,42]$. The reasons for such differences remain unclear and include potential racial/ethnic differences in susceptibility to glycation of haemoglobin $[41,42]$, and underlying average glucose concentrations being higher in African descent populations (and not properly accounted for by adjusting for fasting and post challenge glucose).

One little mentioned but possible contributory factor to population differences in HbAlc levels is iron deficiency. This may increase red cell life and thus HbAlc levels $[43,44]$. It is possible that iron deficiency anaemia in women of child-bearing age contributes to the higher HbAlc levels in women found in our study. Unfortunately, haemoglobin was not measured in the survey, but WHO estimates for the prevalence of iron deficiency anaemia in Barbados suggest that around one in five to one in four women aged 15-49 are anaemic [45]. The potential effect of iron deficiency anaemia on HbAlc levels requires further evaluation. Another, possibly more important, contributory factor to higher HbAlc levels in women compared to men in Barbados is the higher prevalence of obesity, particularly abdominal obesity. Controlling for abdominal obesity, defined using sex-specific cut-points, reduced to non-significant the association of HbAlc defined hyperglycaemia with female sex.

Before drawing conclusions on the implications of the findings reported here, we should acknowledge both the strengths and limitations of the study. A strength is that this is a representative population-based study. Standardised methods were used to collect all data, most importantly to measure FPG and HbAlc. The method of HbAlc measurement used is approved by the NGSP [18] and widely used, and in addition we aligned these values to those from the only reference laboratory in Barbados that uses the gold standard approach of HPLC. Limitations of the study include that it was a relatively small study population, and thus lacks precision to properly investigate some areas of interest, including differences in diabetes prevalence by FPG or HbAlc. In addition, it was an epidemiological study using epidemiological definitions of prediabetes and undiagnosed diabetes; ie, our definitions are based on a single measurement, whereas in clinical practice, and in the absence of clear symptoms, a confirmatory diagnostic test should always be performed [3,11]. Finally, it is worth noting that the kappa statistic to assess agreement between categories based on FPG and HbAlc requires careful interpretation. Kappa values are influenced by the prevalence of the different categories, and when the prevalence is very different (such as the prevalence of diabetes vs no diabetes), Kappa may provide an overly negative summary of the agreement [46]. We recommend therefore that the Kappa values are only used and interpreted alongside the actual crosstabulated data (Table 2). Despite these limitations, our findings demonstrate marked differences between FPG and HbAlc in the identification of hyperglycaemia in the adult population of Barbados.

In conclusion, current guidance recommends the use of both FPG and HbAlc for the diagnosis of diabetes and prediabetes. This study has shown that according to ADA guidance around $44 \%$ of the adult population of Barbados has prediabetes, with a further $6.5 \%$ having previously undiagnosed diabetes. When 
previously diagnosed diabetes is added, roughly two out of three (64\%) adults are classified as having either diabetes or prediabetes and thus the majority of the adult population would be recommended for clinical intervention [11]. By contrast, if WHO diagnostic guidance is followed then roughly one in four adults (25\%) has either diabetes or prediabetes. In very well-resourced settings it might be considered prudent to measure both FPG and HbAlc and manage individuals accordingly, as is recommended [11]. However, in less well-resourced settings, such as in Barbados and most of the Caribbean, our findings indicate that the increasing use of HbAlc to diagnose diabetes and prediabetes could have major implications: for human and financial resources; clinical practice and public health policies; and for health systems that are already struggling to cope with the high and increasing burden of chronic diseases. In addition, there is limited evidence to support whether one approach is better than the other for identifying individuals who will benefit from treatment. In short, the currently available guidance is particularly unhelpful, and potentially damaging (if it leads to less effective use of scarce resources), for situations in which resources are limited. We propose therefore that a pragmatic approach, guided by the currently available evidence, is to use FPG as the diagnostic test for both diabetes and prediabetes and to restrict the label of 'prediabetes' to the narrow range recommended by WHO. Expansion of the prediabetes category, whether by adopting the broader ADA FPG range or using HbAlc criteria, should be contingent upon clear evidence that cost-effective interventions to improve outcomes are available [29].

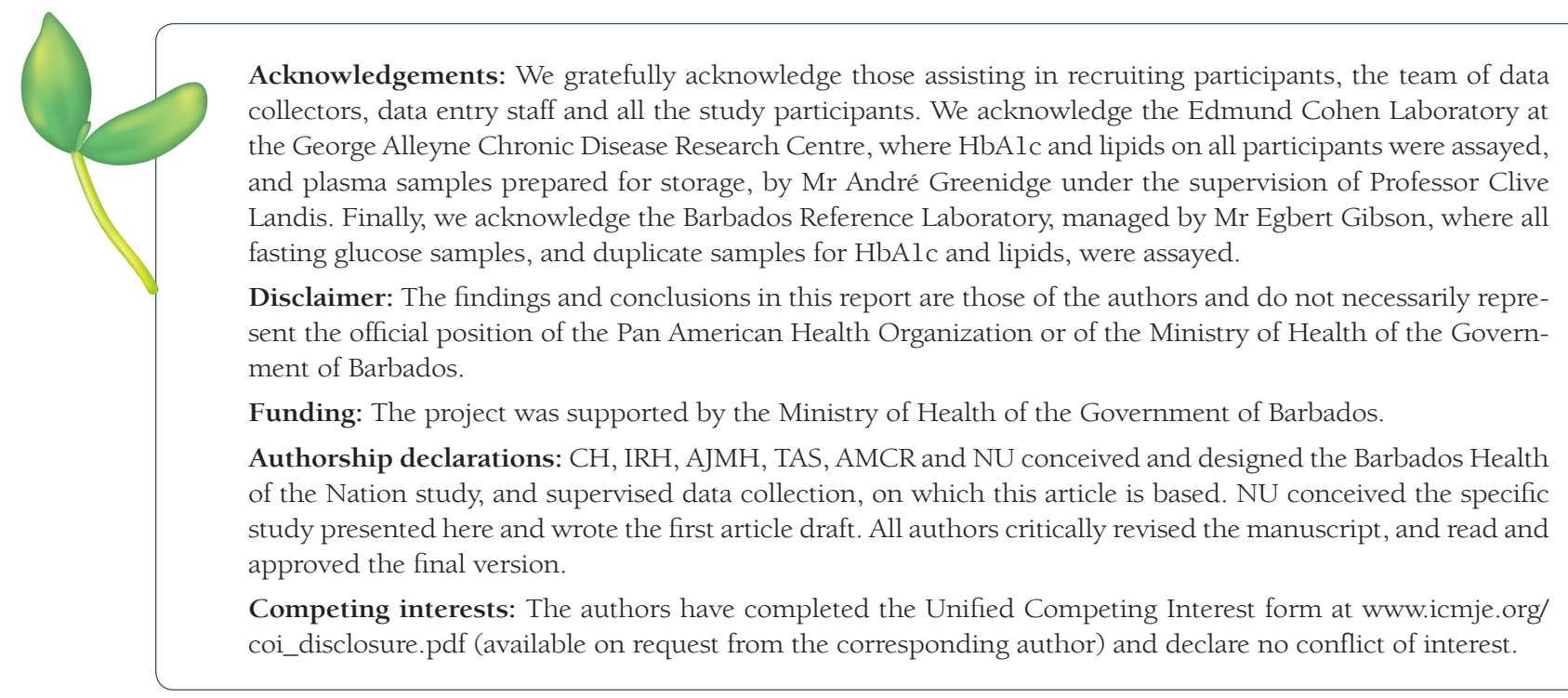

1 International Diabetes Federation. Diabetes Atlas: seventh edition. Brussels: International Diabetes Federation; 2015.

2 American Diabetes Association. Diagnosis and classification of diabetes mellitus. Diabetes Care. 2004;27:S5-S10. Medline:14693921 doi:10.2337/diacare.27.2007.55

3 World Health Organization. Definition and diagnosis of diabetes mellitus and intermediate hyperglycemia: report of a WHO/IDF consultation. Geneva: World Health Organization; 2006.

4 Gillies CL, Abrams KR, Lambert PC, Cooper NJ, Sutton AJ, Hsu RT, et al. Pharmacological and lifestyle interventions to prevent or delay type 2 diabetes in people with impaired glucose tolerance: systematic review and meta-analysis. BMJ. 2007;334:299. Medline:17237299 doi:10.1136/bmj.39063.689375.55

5 The Expert Committee on the Diagnosis and Classification of Diabetes Mellitus. Report of the Expert Committee on the diagnosis and classification of diabetes mellitus. Diabetes Care. 1997;20:1183-97. Medline:9203460 doi:10.2337/diacare.20.7.1183

6 International Expert Committee. International Expert Committee report on the role of the AlC assay in the diagnosis of diabetes. Diabetes Care. 2009;32:1327-34. Medline:19502545 doi:10.2337/dc09-9033

$7 \mathrm{HbAlc}$ and Eestimated average glucose (eAG). Available: http://www.ngsp.org/AlceAG.asp. Accessed: 1 August 2017.

8 Cohen RM, Franco RS, Khera PK, Smith EP, Lindsell CJ, Ciraolo PJ, et al. Red cell life span heterogeneity in hematologically normal people is sufficient to alter HbAlc. Blood. 2008;112:4284-91. Medline:18694998 doi:10.1182/ blood-2008-04-154112

9 World Health Organization. Use of glycated haemoglobin (hbalc) in the diagnosis of diabetes mellitus: Abbreviated report of a WHO Consultation. Geneva: World Health Organization; 2011. 
10 World Health Organization. Definition, diagnosis, and classification of diabetes mellitus and its complications. Report of a WHO consultation. Part 1: Diagnosis and classification of diabetes mellitus. Geneva. World Health Organization; 1999.

11 American Diabetes Association. Standards of medical care in diabetes - 2015. Diabetes Care. 2015;38 Suppl:S4. Medline:25537706 doi:10.2337/dc15-S003

12 Samuels TA, Guell C, Legetic B, Unwin N. Policy initiatives, culture and the prevention and control of chronic non-communicable diseases (NCDs) in the Caribbean. Ethn Health. 2012;17:631-49. Medline:23249261 doi:10.1080/1355785 8.2012 .752072

13 Caribbean Community. Member states and associate members. Available: http://caricom.org/about-caricom/who-we-are/ our-governance/members-and-associate-members/. Accessed: 1 August 2017.

14 Pan American Health Organization/World Health Organization. Communicable Diseases and Health Analysis/Health Information and Analysis. Health Situation in the Americas: Core Indicators 2016. In.: Washington, D.C.: PAHO; 2016.

15 Barabados Statistical Service. 2010 Population and Housing Census. Volume 1. Barbados: Government of Barbados; 2013. Available: www.barstats.gov.bb/files/documents/PHC_2010_Census_Volume_1.pdf. Accessed: 1 August 2017.

16 Howitt C, Hambleton IR, Rose AM, Hennis A, Samuels TA, George KS, et al. Social distribution of diabetes, hypertension and related risk factors in Barbados: a cross-sectional study. BMJ Open. 2015;5:e008869. Medline:26685026 doi:10.1136/bmjopen-2015-008869

17 Kish L. Procedure for objective respondent selection within a household. Journal of the American Sociological Association. 1949;44:380-7. doi:10.1080/01621459.1949.10483314

18 Certified Methods and Laboratories. Available: http://www.ngsp.org/certified.asp. Accessed: 1 August 2017.

$19 \mathrm{HbAlc}$ assay interferences. Available: http://www.ngsp.org/interf.asp. Accessed: 1 August 2017.

20 John WG, Edwards R, Price CP. Laboratory evaluation of the DCA 2000 clinic HbAlc immunoassay analyser. Ann Clin Biochem. 1994;31:367-70. Medline:7979104 doi:10.1177/000456329403100411

21 Lapinleimu H, Viikari J, Jokinen E, Routi T, Salo P, Hollo O, et al. Cholesterol measurement by reflotron dry chemistry in infants, children and adults. Scand J Clin Lab Invest. 1994;54:61-5. Medline:8171273 doi:10.3109/00365519409086511

22 Bowden RG, Kingery PM, Long L. Precision of a dry-chemistry method of lipid screening. Public Health. 2006;120:5726. Medline:16730036 doi:10.1016/j.puhe.2006.03.005

23 Sanchez-Mora C, Rodriguez-Oliva SM, Fernandez-Riejos P, Mateo J, Polo-Padillo J, Goberna R, et al. Evaluation of two HbAlc point-of-care analyzers. Clin Chem Lab Med. 2011;49:653-7. Medline:21323623 doi:10.1515/CCLM.2011.101

24 Bland JM, Altman DG. Comparing methods of measurement: why plotting difference against standard method is misleading. Lancet. 1995;346:1085-7. Medline:7564793 doi:10.1016/S0140-6736(95)91748-9

25 Unwin N, Shaw P. Diabetes mellitus. In: Gulliford D, Tan K, eds. Oxford Textbook of Global Public Health. 6th Ed. Oxford: Oxford University Press; 2015.

26 Manual, version 13: Specification link test for single equation models Available: http://www.stata.com/manuals13/ rlinktest.pdf. Accessed: 1 August 2017.

27 Alberti KG, Eckel RH, Grundy SM, Zimmet PZ, Cleeman JI, Donato KA, et al. Harmonizing the metabolic syndrome: a joint interim statement of the International Diabetes Federation Task Force on Epidemiology and Prevention; National Heart, Lung, and Blood Institute; American Heart Association; World Heart Federation; International Atherosclerosis Society; and International Association for the Study of Obesity. Circulation. 2009;120:1640-5. Medline:19805654 doi:10.1161/CIRCULATIONAHA.109.192644

28 Colagiuri S, Lee CM, Wong TY, Balkau B, Shaw JE, Borch-Johnsen K. Glycemic thresholds for diabetes-specific retinopathy: implications for diagnostic criteria for diabetes. Diabetes Care. 2011;34:145-50. Medline:20978099 doi:10.2337/ dc10-1206

29 Yudkin JS, Montori VM. The epidemic of pre-diabetes: the medicine and the politics. BMJ. 2014;349:g4485. Medline:25028385 doi:10.1136/bmj.g4485

30 Di Angelantonio E, Gao P, Khan H, Butterworth AS, Wormser D, Kaptoge S, et al. Glycated hemoglobin measurement and prediction of cardiovascular disease. JAMA. 2014;311:1225-33. Medline:24668104 doi:10.1001/jama.2014.1873

31 Weber MB, Ranjani H, Staimez LR, Anjana RM, Ali MK, Narayan KM, et al. The Stepwise Approach to Diabetes Prevention: Results From the D-CLIP Randomized Controlled Trial. Diabetes Care. 2016;39:1760-7. Medline:27504014 doi: $10.2337 / \mathrm{dc} 16-1241$

32 Saito T, Watanabe M, Nishida J, Izumi T, Omura M, Takagi T, et al. Lifestyle modification and prevention of type 2 diabetes in overweight Japanese with impaired fasting glucose levels: a randomized controlled trial. Arch Intern Med. 2011;171:1352-60. Medline:21824948 doi:10.1001/archinternmed.2011.275

33 NCD Risk Factor Collaboration. Effects of diabetes definition on global surveillance of diabetes prevalence and diagnosis: a pooled analysis of 96 population-based studies with 331288 participants. Lancet Diabetes Endocrinol. 2015;3:62437. Medline:26109024 doi:10.1016/\$2213-8587(15)00129-1

34 Rosella LC, Lebenbaum M, Fitzpatrick T, Zuk A, Booth GL. Prevalence of prediabetes and undiagnosed diabetes in Canada (2007-2011) according to fasting plasma glucose and HbAlc screening criteria. Diabetes Care. 2015;38:1299-305. Medline:25852207 doi:10.2337/dc14-2474

35 Selvin E, Parrinello CM, Sacks DB, Coresh J. Trends in prevalence and control of diabetes in the United States, 19881994 and 1999-2010. Ann Intern Med. 2014;160:517-25. Medline:24733192 doi:10.7326/M13-2411

$36 \mathrm{Ng}$ M, Fleming T, Robinson M, Thomson B, Graetz N, Margono C, et al. Global, regional, and national prevalence of overweight and obesity in children and adults during 1980-2013: a systematic analysis for the Global Burden of Disease Study 2013. Lancet. 2014;384:766-81. Medline:24880830 doi:10.1016/S0140-6736(14)60460-8 
37 Sumner AE, Thoreson CK, O'Connor MY, Ricks M, Chung ST, Tulloch-Reid MK, et al. Detection of abnormal glucose tolerance in africans is improved by combining alc with fasting glucose: The Africans in America Study. Diabetes Care. 2015;38:213-9. Medline:25338926 doi:10.2337/dc14-1179

38 Ziemer DC, Kolm P, Weintraub WS, Vaccarino V, Rhee MK, Twombly JG, et al. Glucose-independent, black-white differences in hemoglobin Alc levels: a cross-sectional analysis of 2 studies. Ann Intern Med. 2010;152:770-7. Medline:20547905 doi:10.7326/0003-4819-152-12-201006150-00004

39 Selvin E, Steffes MW, Ballantyne CM, Hoogeveen RC, Coresh J, Brancati FL. Racial differences in glycemic markers: a cross-sectional analysis of community-based data. Ann Intern Med. 2011;154:303-9. Medline:21357907 doi:10.7326/00034819-154-5-201103010-00004

40 Herman WH, Ma Y, Uwaifo G, Haffner S, Kahn SE, Horton ES, et al. Differences in AlC by race and ethnicity among patients with impaired glucose tolerance in the Diabetes Prevention Program. Diabetes Care. 2007;30:2453-7. Medline:17536077 doi:10.2337/dc06-2003

41 Herman WH. Do race and ethnicity impact hemoglobin Alc independent of glycemia? J Diabetes Sci Technol. 2009;3:65660. Medline:20144308 doi:10.1177/193229680900300406

42 Herman WH, Cohen RM. Racial and ethnic differences in the relationship between HbAlc and blood glucose: implications for the diagnosis of diabetes. J Clin Endocrinol Metab. 2012;97:1067-72. Medline:22238408 doi:10.1210/jc.20111894

43 English E, Idris I, Smith G, Dhatariya K, Kilpatrick ES, John WG. The effect of anaemia and abnormalities of erythrocyte indices on HbAlc analysis: a systematic review. Diabetologia. 2015;58:1409-21. Medline:25994072 doi:10.1007/s00125015-3599-3

44 Hardikar PS, Joshi SM, Bhat DS, Raut DA, Katre PA, Lubree HG, et al. Spuriously high prevalence of prediabetes diagnosed by HbAlc in young Indians partly explained by hematological factors and iron deficiency anemia. Diabetes Care. 2012;35:797-802. Medline:22323413 doi:10.2337/dc11-1321

45 WHO. The global prevalence of anaemia in 2011. Geneva: World Health Organization; 2015.

$46 \mathrm{Sim}$ J, Wright CC. The kappa statistic in reliability studies: use, interpretation, and sample size requirements. Phys Ther. 2005;85:257-68. Medline:15733050 